\title{
INTERSTATE DIFFERENCES IN PRICE AND INCOME ELASTICITIES: THE CASE OF NATURAL GAS
}

\author{
Yu Hsing*
}

\begin{abstract}
Based on a generalized functional form, this study tests potential spatial differences in the price and income elasticities of demand for natural gas. Empirical results show that the double-log and linear forms can be rejected at the 1 percent or 10 percent level and that price and income elasticities vary significantly with the price of natural gas and income, respectively. Specifically, price elasticities varied from -0.29 for Alaska to -2.24 for Florida, and income elasticities ranged from 0.37 for Alaska to 1.44 for Florida. Since separate elasticities can be estimated for individual states, in empirical work we need not choose a priori the double-log form by assuming a constant elasticity across states.
\end{abstract}

\section{INTRODUCTION}

The demand for natural gas has been studied extensively for a number of reasons. In the residential and commercial sectors, the consumption of natural gas ranked first in 1989 at 7.721 quadrillion btu, followed by the consumption of electricity at $\mathbf{5 . 8 5 6}$ quadrillion btu and the consumption of petroleum at 2.625 quadrillion btu. The natural gas industry was highly regulated in the past. To pursue free market operations and to encourage competition among natural gas producers, the federal government passed the Natural Gas Policy Act (NGPA) in 1978, mandating the phased decontrol of the wellhead price of new gas supplied by 1993. The deregulation of this industry suggests that the study of demand for natural gas is timely and appropriate. Natural gas may serve as a substitute for electricity. In urban areas where piped gas lines are readily available, households can compare the relative costs and benefits of using different forms of energy and make rational decisions to save expenses. Another advantage of using natural gas is that it basically is a clean form of energy, which is vital to many people for environmental reasons.

This study examines potential spatial differences in the elasticity of residential demand for natural gas. The study of interstate differences in elasticity is important because policymakers need to be aware that the effects of federal programs regulating prices and other variables are expected to be different across states, and because the estimation of elasticity at the national or regional level

\footnotetext{
*Associate Professor of Economics, Southeastem Louisiana University. The author is grateful to anonymous referees for insightful comments. The original draft of this paper was presented at the 1990 annual conference of the Southern Economic Association held in New Orleans. The author thanks the participants of the Energy Session for helpful comments.
} 
may be inadequate due to the possibility that within a census region or division, elasticity may vary widely among states. By definition, the price elasticity of demand for natural gas is equal to the percentage change in natural gas consumption divided by the percentage change in the price. Likewise, the income elasticity is the ratio of the percentage change in natural gas consumption to the percentage change in income. Economic theory and empirical work (Chang and Hsing 1991; Maddala and Miller 1989; Gemmill 1980) suggest that the price elasticity in absolute value varies positively with the price. When the price is higher (lower), the demand is more (less) elastic. Since prices for natural gas vary among states, it is expected that (other factors being held constant) states with higher (lower) prices may have more (less) elastic demand.

Similarly, income elasticities vary along an Engel curve and may differ across states. If households regard natural gas as a necessity (normal good), the slope of the Engel curve will decrease as income rises, and the income elasticity will have a value between zero and one. If consumers consider natural gas as a luxury, the slope of the Engel curve will increase as income rises, and the income elasticity will be greater than one.

\section{SURVEY OF LITERATURE}

Major studies of demand for natural gas can be found in Taylor (1977), Griffin (1979), Barnes, Gillingham, and Hagemann (1982), Blattenberger, Taylor, and Rennhack (1983), and Al-Sahlawi (1991), among others. Taylor (1977) first surveyed price and income elasticities of demand for major types of energy. He reported that short-term price elasticities of demand for natural gas ranged from -0.14 to -0.38 , and long-term price elasticities varied from -0.69 to -3.09 . Based on the translog share equations and on Zellner's iterative method and pooled data for 18 OECD countries during 1955-72, Griffin (1979) found that the short-term and long-term price elasticities for residential natural gas were estimated to be 0.95 and -2.61 , respectively.

Using the 1972-73 Consumer Expenditure Survey of over 10,000 households conducted by the Bureau of the Census, Barnes, Gillingham, and Hagemann (1982) studied the demand for natural gas in the short run. Variables considered were income, the marginal price of natural gas, the rate structure premium, demographic variables, and a vector of appliance-specific factors. The instrumental variable technique was employed. A hybrid of the log and level forms was used in the regression. Their major findings are that the price elasticity of demand was -0.682 and the income elasticity was 0.151 . However, they found 
that variations existed across end-use categories such as space heating, central air conditioning, and water heating.

Blattenberger, Taylor, and Rennhack (1983) estimated short-term and longterm demand elasticities for natural gas based on pooled time series and crosssectional data for 48 states during 1960-75. In their extensive research, variables included in the regression were income, marginal price of natural gas, marginal price of electricity, price of fuel oil, fixed charge for electricity, fixed charge for natural gas, heating-degree days, and cooling-degree days. Several models were considered, and the variance-component technique was used to estimate the parameters. Their estimates of demand elasticities for marginal price of natural gas ranged from -0.049 to -0.333 , and income elasticities for natural gas ranged between 0.026 and 0.769 . They also showed that Durbin's h statistics for time series data were between -2 and 2 for only four states, suggesting that autocorrelation was not a problem. However, heteroscedasticity was not eliminated in the equation for the number of customers.

Al-Sahlawi (1991) reviewed and summarized previous studies of demand for natural gas. He found that estimated price and income elasticities varied widely, depending upon data sources, sample periods, types of users, geographical areas, and other factors. For example, estimated short-term price elasticities varied from -0.046 to -0.95 , and long-term price elasticities ranged from -0.63 to -4.60 . Estimated short-term and long-term income elasticities lay in the ranges of 0.0110.955 and $0.133-6.40$, respectively.

\section{THE MODEL AND METHODOLOGY}

The residential demand for natural gas can be expressed as

$$
Q G_{i t}=\beta_{1}+\beta_{2} P G_{i t}+\beta_{3} D Y_{i t}+\beta_{4} P E_{i t}+\beta_{5} H D_{i t}+U_{i t}
$$

where $Q G$ is demand for natural gas, $P G$ is the price of natural gas, $D Y$ is per capita disposable personal income, $P E$ is the price of residential electricity, $H D$ is the number of heating-degree days, $U$ is the disturbance term, $i$ is an individual state, and $t$ is time. It is expected that natural gas consumption is negatively correlated with its own price and is positively associated with per capita disposable personal income, the price of residential electricity due to potential substitution of electricity for natural gas, and heating-degree days. Regional and time dummy variables will also be considered in empirical work.

For any variable $X$, it is transformed as $\left(X_{u t}^{\lambda}-1\right) / \lambda$, where $\lambda$ is the Box-Cox (1964) transformation parameter. It can be shown that Equation (1) reduces to a 
double-log form when $\lambda=0$ and becomes a linear form when $\lambda=1$. The elasticity of $Q G$ with respect to $P G$ or $D Y$ can be shown to be

$$
\begin{aligned}
& E_{p i t}=\beta_{2}\left(P G_{i t} / Q G_{i t}\right)^{\lambda} \\
& E_{y i t}=\beta_{3}\left(D Y_{i t} / Q G_{i t}\right)^{\lambda}
\end{aligned}
$$

Equation (2) states that if $\lambda$ is positive, the elasticity of $Q G$ with respect to $P G$ or $D Y$ in absolute value varies positively with $P G$ or $D Y$ but negatively with $Q G$. If $\lambda$ is estimated to be negative, the reverse relationships hold. Note that in the double-log form, the price and income elasticities are constant and equal to $\beta_{2}$ and $\beta_{3}$, respectively. Major drawbacks of the double-log form are that it is inconsistent with the theory of utility maximization and that it does not satisfy the integratibility condition.

The log-likelihood function for Equation (1), except for a constant, is

$$
L(\lambda)=-(N / 2) \ln \hat{\sigma}^{2}+(\lambda-1) \sum \ln Q G_{i t}
$$

where $N$ is the sample size, and $\hat{\sigma}^{2}$ is the estimated residual variance. The test statistic has $\chi^{2}$ distribution and is given by

$$
J(\lambda)=2[L(\hat{\lambda})-L(\lambda)] \sim \chi_{\alpha}^{2}(V)
$$

where $L(\hat{\lambda})$ is the maximized log-likelihood function without any restriction, whereas $L(\lambda)$ is the restricted $\log$-likelihood function.

\section{EMPIRICAL RESULTS}

Total residential consumption of natural gas, the number of residential consumers, the price of natural gas $(P G)$, and the price of residential electricity $(P E)$ for 49 states and the District of Columbia from 1985 to 1989 came from the State Energy Data Report: Consumption Estimates, State Energy Price and Expenditure Report, and Natural Gas Annual, Energy Information Administration, U.S. Department of Energy. Hawaii is not included in the sample due to lack of data. The dependent variable $(Q G)$ is derived by dividing total residential consumption of natural gas by the number of residential consumers. $Q G$ is measured in million btu per consumer. The prices of natural gas and residential electricity are measured in dollars per million btu. Per capita disposable personal income (DY) came from the Survey of Current Business, Bureau of Economic Analysis, U.S. Department of Commerce. Heating-degree days came from the Climatography of the United States, U.S. National Oceanic and Atmospheric Administration and 
were based on 30-year averages during 1951-80. To reduce multicollinearity, $H D$ is redefined as the number of heating-degree days minus the mean heating-degree days. Because some of $H D$ have negative values, it is not transformed. Prices and income are deflated by the regional consumer price indexes and are expressed in real terms.

Empirical results and relevant statistics are reported in Table 1. Estimated regressions for the general, double-log, and linear models are presented for comparison purposes. In the general form, all of the explanatory variables have the expected signs and are significant at the 1 percent or 5 percent level. The positive sign of PE suggests that natural gas and electricity are substitutes. Dummy variables are also considered to see if intercepts will change among regions and

TABLE 1

Estimated Regressions and Other Statistics: Demand for Natural Gas

\begin{tabular}{lccc}
\hline \hline Variable & General & Double-log & Linear \\
\hline PG & -8.291 & -0.738 & -15.181 \\
& $(-10.755)$ & $(-9.193)$ & $(-10.936)$ \\
DY & 0.474 & 0.458 & 0.476 \\
& $(6.050)$ & $(4.610)$ & $(6.280)$ \\
PE & 0.562 & 0.056 & 0.915 \\
& $(2.161)$ & $(0.738)$ & $(2.526)$ \\
HD & 0.003 & 0.00009 & 0.009 \\
& $(11.094)$ & $(9.897)$ & $(11.253)$ \\
SO & 5.703 & 0.121 & 15.153 \\
& $(3.617)$ & $(2.616)$ & $(3.865)$ \\
WE & -2.516 & -0.103 & -5.255 \\
& $(-1.916)$ & $(-2.617)$ & $(-1.617)$ \\
D5 & 7.467 & 0.176 & 19.067 \\
& $(5.747)$ & $(4.680)$ & $(5.890)$ \\
D6 & 4.223 & 0.112 & 10.428 \\
& $(3.287)$ & $(2.985)$ & $(3.266)$ \\
Int. & 38.412 & 3.309 & 92.153 \\
& $(8.304)$ & $(7.487)$ & $(8.870)$ \\
$\lambda$ & 0.800 & 0.000 & 1.000 \\
L $(\lambda)$ & -1052.930 & -1075.970 & -1054.360 \\
$\bar{R}^{2}$ & 0.642 & 0.593 & 0.646 \\
\hline
\end{tabular}

The dependent variable (QG) is natural gas consumption per consumer.

PG: price of natural gas.

DY: per capita disposable personal income.

$\mathrm{PE}$ : price of residential electricity.

$\mathrm{HD}$ : heating degree days.

SO: the South; WE: the West; D5: time dummy for 1985; D6: time dummy for 1986; and Int.: the constant term.

$L(\lambda)$ : the maximized value of the log-likelihood function.

Figures in parentheses are t-ratios. 
across time. Results show that the South has a greater intercept, whereas the West has a smaller intercept. The value of $\lambda$ is estimated to be 0.80 when the loglikelihood function is maximized. In the double-log form, the coefficient of PE is insignificant, suggesting that natural gas and electricity are not competing goods.

To see the appropriateness of the constant elasticity hypothesis, we first consider testing the double-log form $\left(\mathrm{H}_{\mathrm{o}}: \lambda=0\right)$ versus the general form $\left(\mathrm{H}_{\mathrm{a}}: \lambda \neq 0\right)$. The value of the test statistic is calculated to be 46.08 . Since it is greater than the critical value of 6.635 with one degree of freedom at the 1 percent level, the double-log form can be rejected, which implies that the constant elasticity hypothesis is inappropriate and that price and income elasticities vary across states. The linear form is examined as well. The likelihood ratio test indicates that the linear form can be rejected at the 10 percent level.

Based on Equation (2) and the estimated parameters, estimated price and income elasticities of demand for natural gas for 49 states and the District of Columbia, based on the census divisions, are compiled in Table 2.

Due to limited space, only 1989 estimates are presented. As shown, price elasticities varied widely from -0.29 for Alaska to -2.24 for Florida. The price elasticity at the mean is calculated to be -0.77 . Estimated price elasticities in absolute value are lower in IL $(-0.43), \mathrm{MI}(-0.46)$, and $\mathrm{MN}(-0.49)$, mainly because of lower prices for natural gas, but higher in ME (-1.43), SC (-1.15), and AZ $(-1.40)$ due to higher prices in these states. The correlation coefficient between the price elasticity and the price of natural gas is calculated to be 0.68 . Hence, empirical results in this study are consistent with economic theory that price elasticities in absolute value vary positively with the price of a commodity. By contrast, in the double-log form, the price elasticity is estimated to be -0.74 across all states without regard to the spatial factor. If the double-log form is chosen a priori, we will draw a conclusion that the demand for natural gas is less elastic. As a matter of fact, the demand for natural gas may be more elastic, less elastic, or unitarily elastic, depending upon the states under consideration, the price of natural gas, and other relevant factors.

Estimated income elasticities ranged from 0.37 for Alaska to 1.44 for Florida. The income elasticity at the mean is calculated to be 0.53 . Except for Florida, households regard natural gas as a normal good because the values of the income elasticity are between zero and one. The relationship between the income elasticity and the size of income is positive, with the correlation coefficient calculated to be 0.23 . 
TABLE 2

Estimated Price and Income Elasticities of Demand for Natural Gas by State

\begin{tabular}{|c|c|c|c|c|c|}
\hline State & $E_{p}$ & $\mathbf{E}_{\mathbf{y}}$ & State & $\mathbf{E}_{\mathbf{p}}$ & Ey $_{\mathbf{y}}$ \\
\hline New England & & & E.S. Central & & \\
\hline CT & -0.90 & 0.70 & AL & -0.98 & 0.61 \\
\hline ME & -1.43 & 0.90 & $\overline{K Y}$ & -0.55 & 0.44 \\
\hline MA & -0.78 & 0.62 & MS & -0.83 & 0.55 \\
\hline NH & -0.78 & 0.62 & TN & -0.70 & 0.58 \\
\hline RI & -0.81 & 0.55 & & & \\
\hline VT & -0.41 & 0.25 & W.S. Central & & \\
\hline Middle Atlantic & & & $\begin{array}{l}\text { AR } \\
\text { LA }\end{array}$ & $\begin{array}{l}-0.71 \\
-1.02\end{array}$ & $\begin{array}{l}0.51 \\
0.66\end{array}$ \\
\hline NJ & -0.73 & 0.67 & OK & -0.63 & 0.50 \\
\hline NY & -0.83 & 0.61 & TX & -0.86 & 0.66 \\
\hline \multirow{2}{*}{ PA } & -0.60 & 0.46 & & & \\
\hline & & & Mountain & & \\
\hline E.N. Central & & & $\mathrm{AZ}$ & -1.40 & 0.88 \\
\hline IL & -0.43 & 0.42 & $\mathrm{CO}$ & -0.61 & 0.58 \\
\hline IN & -0.59 & 0.45 & ID & -0.75 & 0.57 \\
\hline MI & -0.46 & 0.40 & MT & -0.53 & 0.45 \\
\hline $\mathbf{O H}$ & -0.51 & 0.42 & NV & -0.86 & 0.72 \\
\hline \multirow[t]{2}{*}{ WI } & -0.63 & 0.47 & NM & -0.84 & 0.56 \\
\hline & & & UT & -0.55 & 0.39 \\
\hline W.N. Central & & & WY & -0.54 & 0.45 \\
\hline IA & -0.56 & 0.48 & & & \\
\hline $\mathrm{KS}$ & -0.55 & 0.53 & \multicolumn{2}{|c|}{ Pacific contiguous } & \\
\hline MN & -0.49 & 0.45 & $\mathrm{CA}$ & -0.96 & 0.85 \\
\hline MO & -0.59 & 0.51 & OR & -0.90 & 0.63 \\
\hline NE & -0.56 & 0.50 & WA & -0.71 & 0.60 \\
\hline ND & -0.51 & 0.41 & & & \\
\hline \multirow[t]{2}{*}{ SD } & -0.57 & 0.46 & Pacific noncor & tiguous & \\
\hline & & & AK & -0.29 & 0.37 \\
\hline
\end{tabular}

South Atlantic

$\begin{array}{lll}\text { DE } & -0.85 & 0.64 \\ \text { DC } & -0.71 & 0.52 \\ \text { FL } & -2.24 & 1.44 \\ \text { GA } & -0.89 & 0.61 \\ \text { MD } & -0.75 & 0.62 \\ \text { NC } & -0.93 & 0.60 \\ \text { SC } & -1.15 & 0.67 \\ \text { VA } & -0.74 & 0.56 \\ \text { WV } & -0.61 & 0.40\end{array}$

Elasticity at the Mean

$-0.77$

0.53

$\mathrm{E}_{\mathrm{p}}$ : the price elasticity of demand for natural gas.

Ey: the income elasticity of demand for natural gas. 


\section{SUMMARY AND CONCLUSIONS}

The study of interstate differences in demand elasticities is significant because government officials can better predict different effects of changes in price and other relevant variables on demand for a commodity across states, and because the estimation of demand elasticities at the national or regional level may not be close enough to account for potential variations in demand elasticities among states. In this study, we have examined regional differences in the price and income elasticities of demand for natural gas. Based on pooled data for 50 states during 1985-89, we have found that the double-log and linear forms can be rejected at the 1 percent and 10 percent levels, respectively, that the constant demand elasticity hypothesis is inappropriate, and that price and income elasticities vary among states. These findings have the following implications. First, the theoretical model of the regional study of demand for a commodity should be consistent with economic theory, price elasticity varies positively with the own price, and income elasticity changes along an Engel curve. Second, in regional studies, functional forms should be tested first. Although the double-log form has its advantage and convenience, it may not capture the variations in elasticities across states. Third, previous studies based on the double-log form need to be reexamined because results may change and hypothesis tests may be invalidated. Future research may use the same methodology to examine possible regional differences in demand elasticities for other energy items such as residential electricity and gasoline consumption.

\section{REFERENCES}

Al-Sahlawi, Mohammed A. "The Demand for Natural Gas: A Survey of Price and Income Elasticities." Energy Journal (1991): 77-90.

Barnes, Roberta O., Robert F. Gillingham, and Robert P. Hagemann. "The Short-Run Residential Demand for Natural Gas." Energy Journal 3 (1982): 59-72.

Blattenberger, Gail R., Lester D. Taylor, and Robert K. Rennhack. "Natural Gas Availability and the Residential Demand for Energy." Energy Journal 4 (1983): 23-45.

Box, George E. P., and David R. Cox. "An Analysis of Transformation." Journal of the Royal Statistical Association, Series B (1964): 211-243.

Breusch, T. S., and Adrian R. Pagan. "A Simple Test for Heteroscedasticity and Random Coefficient Variation." Econometrica 47 (1979): 1287-1294. 
Chang, Hui S. "Functional Forms and the Demand for Meat in the United States." Review of Economics and Statistics 59 (1977): 355-359.

Chang, Hui S., and Yu Hsing. "The Demand for Residential Electricity: New Evidence on Time-Varying Elasticities." Applied Economics 23 (1991): 1251-1256.

Fichtenbaum, Rudy H., and John P. Blair. "Regional Differences in Labor Demand in the United States." Review of Regional Studies 19 (1989): 72-76.

Gemmill, Gordon T. "Using the Box-Cox Form for Estimating Demand: Comment." Review of Economics and Statistics 62 (1980): 147-148.

Glejser, H. "A New Test for Homoscedasticity." Journal of the American Statistical Association (1969): 316-323.

Goss, Ernest, and Hui S. Chang. "Changes in Elasticities of Interstate Migration: Implications of Alternative Functional Forms." Journal of Regional Science 23 (1983): 223-232.

Griffin, James M. Energy Consumption in the OECD: 1880-2000. Cambridge, Mass.: Ballinger Publishing Company, 1979.

Hsing, Yu. "A Note on Functional Forms and the Urban-Size Distribution." Journal of Urban Economics 27 (1990): 73-79.

Kmenta, Jan. Elements of Econometrics. 2d ed. New York: Macmillan, 1986.

Maddala, G. S., and Ellen Miller. Microeconomics: Theory and Applications. New York: McGraw-Hill, 1989.

Taylor, Lester D. "The Demand for Energy: A Survey of Price and Income Elasticities." In International Studies of the Demand for Energy, edited by E. D. Nordhaus. Amsterdam: North Holland Publishing Co., 1977.

Zarembka, Paul. "Transformation of Variables in Econometrics." In Frontiers in Econometrics, edited by Paul Zarembka, 81-104. New York: Academic Press, 1974. 